\title{
Case series of paediatric adnexal torsion: rare yet urgent entity
}

\section{Vineet Mishra*, Shaheen Hokabaj, Priyankur Roy, Rohina Aggarwal, Bhumika Vyas, Neha Mehta}

Department of Obstetrics and Gynecology, IKDRC, Ahmedabad, Gujarat, India

Received: 24 October 2016

Accepted: 23 November 2016

\author{
*Correspondence: \\ Dr. Vineet Mishra, \\ E-mail: vineet.mishra.ikdrc@gmail.com
}

Copyright: (c) the author(s), publisher and licensee Medip Academy. This is an open-access article distributed under the terms of the Creative Commons Attribution Non-Commercial License, which permits unrestricted non-commercial use, distribution, and reproduction in any medium, provided the original work is properly cited.

\begin{abstract}
Ovarian torsion is a true emergency which warrants early diagnosis and timely surgical management to avoid the catastrophic consequences of further adnexal injury. In paediatric population, this is especially dangerous as the condition can go undiagnosed because of its rarity and nonspecific presentation of disease. This leads to delay in surgical exploration and loss of ovarian function. We encountered 6 cases of ovarian torsion in paediatric age group during a period of 2 years, at a tertiary care hospital in Ahmedabad. After enquiry of the symptoms and a series of investigations, a provisional diagnosis of torsion ovary was made and they were taken up for surgery. Intraoperatively all the patients were found to have non-salvageable ovary and fallopian tube on the affected side, and subsequently they underwent salpingo-oophorectomy. Diagnosis of ovarian torsion requires clinician awareness and a high degree of suspicion. Conservative surgery, in the form of ovarian detorsion can be tried in cases of ischemia but if ovarian necrosis has occurred, then salpingo-oophorectomy is performed as the last resort.
\end{abstract}

Keywords: Conservative surgery, Ovarian torsion, Paediatric age group, Salpingo-oophorectomy

\section{INTRODUCTION}

Ovarian torsion is the fifth most common gynaecologicalsurgical emergency. Women older than 20 years account for almost $70 \%$ of cases. ${ }^{1}$ In women aged less than 20 years, an estimated incidence of ovarian torsion was 4.9 per $100000 .^{2}$

Ovarian torsion is the twisting of an ovary on its ligamentous supports and results in a compromised blood supply. Adnexal torsion is a term that is inclusive of either twisting of the ovary, fallopian tube, or both. ${ }^{3}$ Initially, there is obstruction of venous and lymphatic drainage with sparing of arterial supply leading to ovarian oedema and enlargement which overtime causes capsule to stretch. Ultimately, arterial thrombosis ensues leading to ischemia, infarction and necrosis of ovary. If left untreated, further, can cause systemic infection and inflammation. ${ }^{4}$ Torsion is more common on right side (3:2), possibly either because of the sigmoid colon limiting the movement on left side or a hypermobile cecum on the right that is more permissive to movement and could also be due to longer right ovarian ligament. ${ }^{5}$

The primary imaging modality for evaluation of ovarian torsion is ultrasonography. The features of ovarian torsion includes a unilateral enlarged ovary, uniform peripheral cystic structures, a coexistent mass within the affected ovary, free pelvic fluid, lack of arterial or venous flow, and a twisted vascular pedicle. The presence of flow at colour Doppler imaging does not reliably exclude torsion but instead suggest that the ovary may be viable. ${ }^{3}$

Data about the characteristics of pre-pubertal and adolescent girls with ovarian torsion are limited. In 2001, one review of 51 patients aged 16 years and younger with ovarian torsion concluded that most ovarian torsions were caused by ovarian pathologic features and that salvage was rare after 8 hours of abdominal pain. No ovaries were salvaged in this series because all 51 patients 
underwent salpingo-oophorectomy. ${ }^{6}$ These reports show that the poor ovarian salvage is due to delay in diagnosis and nonspecific symptoms.

We report a series of 6 cases during a period of 2 years at a tertiary care level hospital in Ahmedabad. The objective is to understand detailed nature of its presentation, reliable diagnostic tests, need for early diagnosis and timely surgical intervention to salvage the ovary in paediatric population.

\section{CASE REPORT}

We encountered 6 cases of ovarian torsion in paediatric age group during the period of 2 years, from August 2014 to July 2016 at Institute of Kidney Diseases and Research Centre, Ahmedabad. These cases presented to the Gynaecology OPD and Emergency Medicine Unit, IKDRC with varied clinical features (Table 1). The patients underwent a battery of investigations which were performed to reach the diagnosis (Table 2).

Intra-operatively, the ovary and fallopian tube on the affected side were assessed and found to be oedematous and necrosed in all the patients. Thus, all the patients underwent salpingo-oophorectomy on the affected side and the specimen was sent for histopathological examination (Table 3). The patients are now on regular follow-up and have no recurrence of symptoms or cyst in the contralateral ovary.

Table 1: Clinical features of the patients.

\begin{tabular}{|lllll|l|}
\hline Cases & $\begin{array}{l}\text { Age } \\
\text { (years) }\end{array}$ & $\begin{array}{l}\text { Age at menarche } \\
\text { (years) }\end{array}$ & $\begin{array}{l}\text { Pain localization and } \\
\text { duration }\end{array}$ & Other symptoms & Palpable mass \\
\hline 1 & 7 & No & Lower abdomen for 7 days & No & No \\
\hline 2 & 9 & No & Lower abdomen for 4 days & No & Yes \\
\hline 3 & 11 & No & Left iliac fossa for 6 days & Vomiting & Yes \\
\hline 4 & 12 & No & Left iliac fossa for 10 days & Vomiting & No \\
\hline 5 & 14 & 13 & Lower abdomen for 5 days & Vomiting and Fever & No \\
\hline 6 & 14 & 14 & Right iliac fossa for 2 days & Fever & No \\
\hline
\end{tabular}

Table 2: Investigations performed.

\begin{tabular}{|c|c|c|c|}
\hline Cases & Ultrasonography and CT Scan Findings & $\begin{array}{l}\text { TLC } \\
\text { (cu.mm) }\end{array}$ & $\begin{array}{l}\text { Duration from initial } \\
\text { symptoms to surgery }\end{array}$ \\
\hline 1 & Right complex dermoid cyst $-5.4 \times 3.5 \mathrm{~cm}$ & 8,740 & 7 days \\
\hline 2 & Left ovarian cyst $-10 \times 9 \mathrm{~cm}$ & 9,370 & 6 days \\
\hline 3 & $\begin{array}{l}\text { Left enlarged ovary with multiple follicles } 6.4 \times 3.0 \mathrm{~cm}-\text { ?Torsion } \\
\text { (Figure 1) }\end{array}$ & 9,500 & 7 days \\
\hline 4 & $\begin{array}{l}\text { Left ovarian cyst }-10.5 \times 6.8 \mathrm{~cm} \text { with ovarian torsion with left } \\
\text { hydroureteronephrosis }\end{array}$ & 9,340 & 11 days \\
\hline 5 & $\begin{array}{l}\text { USG - Right ovarian cyst } 12 \times 12 \mathrm{~cm} \text {; right pelvic kidney, CT scan - } \\
\text { right ovarian mass } 15 \times 9 \mathrm{~cm} \text { with mixed echogenicity (Figure } 2 \text { ) }\end{array}$ & 14,260 & 7 days \\
\hline 6 & Right ovarian cyst $-5.5 \times 6.2 \mathrm{~cm}$ & 15,270 & 2 days \\
\hline
\end{tabular}

\section{DISCUSSION}

Paediatric ovarian torsion is a rare entity which is difficult to diagnose because of nonspecific nature of its presentation and as it mimics other common diagnoses. In our case series, patient's age ranged from 7 to 14 years with an average of 12 years. The mean age of presentation in other paediatric ovarian torsion case studies ranged from 9 to 12.5 years. This may be explained by preponderance of ovarian cyst in premenarchal and menarchal girls. ${ }^{5}$
In all the patients who reported to our hospital, lower abdominal pain was a common complaint. 3 patients had generalized lower abdomen pain and another 3 patients had pain localized to the site of torsion. The duration of pain was more than 48 hours in all our patients which was in contrast to previous studies. ${ }^{5}$ Other associated clinical signs and symptoms were vomiting in 3 patients, fever in 2 patients and palpable mass was found only in 2 patients. This clinical presentation was consistent with other studies, in which most common presenting symptoms were abdominal pain and vomiting. ${ }^{7-11}$ Lo et al in their study found that the diagnosis of ovarian torsion 
was missed in $50 \%$ of cases as the clinical signs and symptoms were nonspecific. ${ }^{7}$

In our study, 3 patients had right ovarian torsion and 3 patients had left ovarian torsion. Oskayli et al in their retrospective study involving 41 patients, detected rightsided torsion in $25(59.5 \%)$, and left-sided one was detected in $17(40.5 \%)$ ovaries. ${ }^{10}$

Table 3: Surgical and histopathological examination report.

\begin{tabular}{|c|c|c|c|}
\hline Cases & Intraoperative findings & Mode of Surgery & Histopathology \\
\hline 1 & $\begin{array}{l}\text { Right dermoid cyst with torsion of ovary and } \\
\text { tube (Figure } 4 \text { ) }\end{array}$ & Laparotomy & $\begin{array}{l}\text { Mature cystic teratoma with } \\
\text { torsion }\end{array}$ \\
\hline 2 & $\begin{array}{l}\text { Left necrotic ovary }-10 \times 9.5 \mathrm{~cm}, 2 \text { twists } \\
\text { present at the origin }\end{array}$ & Laparoscopy & $\begin{array}{l}\text { Simple epithelial cyst with ovarian } \\
\text { torsion }\end{array}$ \\
\hline 3 & $\begin{array}{l}\text { Left enlarged ovary with torsion } \\
\text { (Figure 3) }\end{array}$ & Laparoscopy & $\begin{array}{l}\text { Ovarian and fallopian tube shows } \\
\text { ischemic necrosis }\end{array}$ \\
\hline 4 & $\begin{array}{l}\text { Left ovarian mass of } 10 \times 12 \mathrm{~cm} \text { with torsion } \\
\text { of ovary and tube }\end{array}$ & Laparoscopy & $\begin{array}{l}\text { Haemorrhagic corpus luteum cyst } \\
\text { with necrosis }\end{array}$ \\
\hline 5 & $\begin{array}{l}\text { Right ovarian cyst } 12 \times 12 \mathrm{~cm} \text {, haemorrhagic } \\
\text { cyst }\end{array}$ & Laparoscopy & $\begin{array}{l}\text { Haemorrhagic ovarian cyst with } \\
\text { torsion }\end{array}$ \\
\hline 6 & $\begin{array}{l}\text { Right necrosed tube and ovarian mass } \\
10 \times 9 \times 2.5 \mathrm{~cm} \text {; } \\
\text { Ovarian ligament - oedematous }\end{array}$ & Laparoscopy & $\begin{array}{l}\text { Right Haemorrhagic cyst with } \\
\text { salpingitis } \\
\text { with ovarian torsion }\end{array}$ \\
\hline
\end{tabular}

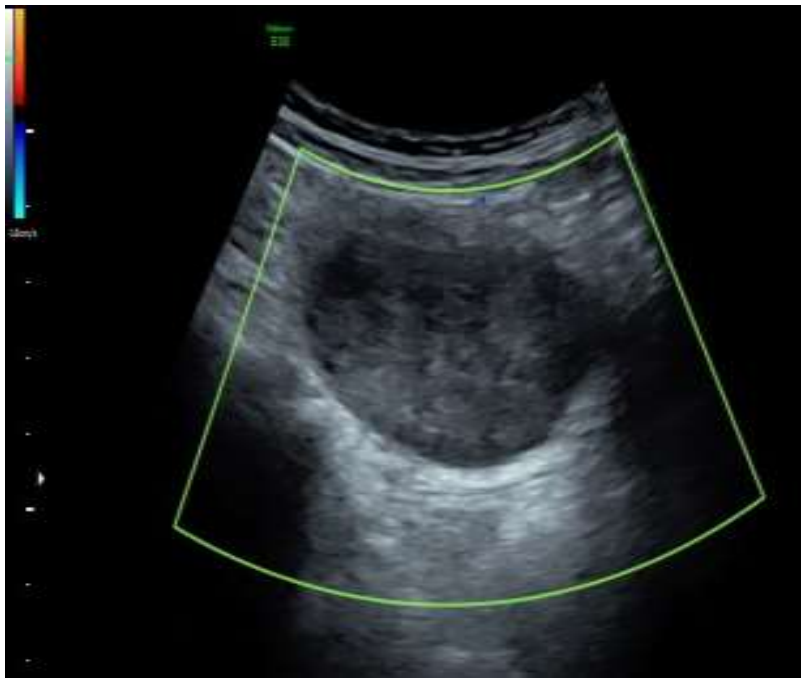

Figure 1: USG Doppler showing left enlarged ovary and fallopian tube with no colour flow - suggestive of torsion adnexa.

Out of 6 patients, 4 were pre-menarchal and 2 were postmenarchal in our study. In the largest paediatric series of ovarian torsion by Kokoska et al, roughly half of the patients were postmenarchal. ${ }^{12}$ Though in many previous studies, leucocytosis was present in majority of cases of ovarian torsion, but in our study, it was found in only 2 patients. ${ }^{5,12}$ However, generalizations regarding leucocytosis in ovarian torsion are difficult because of different studies having varied cut-off criteria.

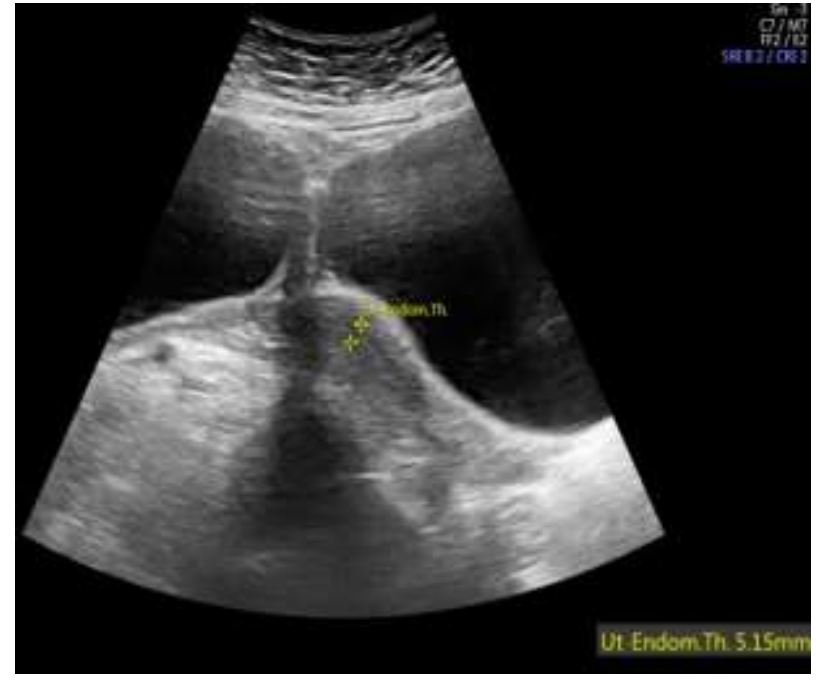

Figure 2: USG showing small uterus with right haemorrhagic adnexal cyst.

The diagnosis of ovarian torsion is usually made with ultrasonography. It is most feasible initial investigation as it is readily available, no radiation exposure and can differentiate from other common causes of acute abdominal pain. Grayscale ultrasound findings include an enlarged ovary or mass, free fluid, thickening of cyst wall, twisted pedicle; although up to $5 \%$ of torsed ovaries have been reported to be of normal size. ${ }^{13}$ Ovarian volume with an ultrasound measured length of more than $5 \mathrm{~cm}$ is often associated with ovarian torsion. ${ }^{14}$ 


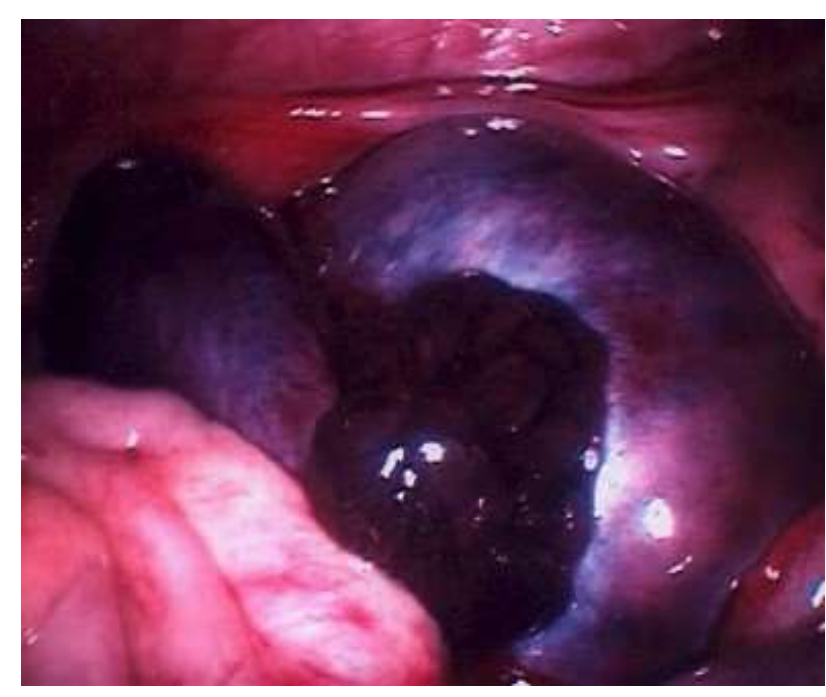

Figure 3: Laparoscopic image showing necrosed ovary and fallopian tube.

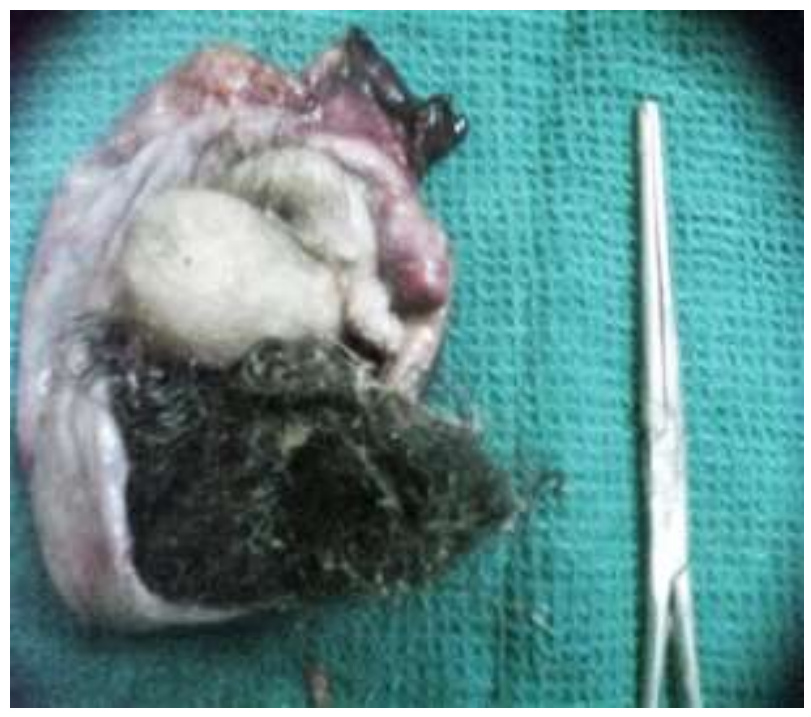

Figure 4: Laparotomy specimen of dermoid cyst excised from a seven year old girl.

Ultrasound with Doppler imaging demonstrated enlarged ovary, ovarian mass of more than $5 \mathrm{~cm}$ ipsilateral to pain site, twisted pedicle in 5 out of 6 cases in our study. Only one pre-menarchal girl had an enlarged ovary with torsion. CT scan was done in only 1 case as she was a patient of post-renal transplant and differentiation from pelvic kidney was required. Ashwal et al showed pathologic findings on ultrasonography in 28 (73.7\%) patients, mainly an enlarged ovary in $11(28.9 \%)$ patients and Doppler findings were abnormal in only 15 patients. ${ }^{9}$ Ultrasound is found to have only $51 \%^{15}$ to $75 \%{ }^{16}$ sensitivity in detecting torsion. Presence of arterial or venous flow does not exclude the diagnosis of ovarian torsion as there is dual blood supply from ovarian and uterine arteries which provide persistent arterial blood flow and symptoms are usually related to venous engorgement before arterial blood supply is compromised. ${ }^{5,13}$ Sonography with or without Doppler is neither reliable in diagnosis nor in excluding torsion. CT scan and MRI imaging can be used to diagnose ovarian torsion in inconclusive ultrasound findings. Subacute ovarian haemorrhage and abnormal enhancement is usually seen as their characteristic patterns on CT scan and MRI.

Hence, use of laparoscopy as a diagnostic modality should be liberal particularly in paediatric patients with pelvic pain and a pelvic mass of more than $5 \mathrm{~cm}$, as it improves the rate of ovarian salvagability. ${ }^{14}$ In our series the mean duration from onset of symptoms to reporting to our hospital was more than 48 hours in all cases. Hence, all patients underwent surgical management - 5 patients by laparoscopy and one patient underwent laparotomy due to pre-operative diagnosis of large dermoid cyst.

Intraoperative findings included torsion with bluish black necrosed ovary and tubes $(n=6)$, dermoid cyst $(n=1)$, haemorrhagic cyst $(n=4)$ and enlarged ovary $(n=1)$. Medial rotation, defined as clockwise rotation of the left adnexa or counter clockwise rotation of the right adnexa, with the proximal (lateral) segment of the infundibulopelvic ligament serving as the referral point was noted in majority of cases $(n=5)$ which was in concordance with other study. ${ }^{17}$ All patients underwent salpingo-oophorectomy. Jennifer et al18 in their case series, had a salvage rate of $40 \%$ among those who were operated within 8 hours of diagnosis; 33\% among those operated within 24 hours of diagnosis; and none among those with operative intervention later than 24 hours. Laparoscopic procedure is recommended over laparotomy because of its advantages of shorter hospital stay, less postoperative complications and a cosmetic scar. $^{18}$

Spinellie et al in their retrospective literature review and statistical analysis found that conservative surgery approach has slowly increase from 28 to $45 \% .{ }^{19}$ Recent studies show more conservative approach such as laparoscopic detorsion along with strong consideration for oophoropexy. Normal ovarian function has been reported when detorsion has been performed within 72 hours of torsion. ${ }^{5}$ In several studies, follow-up evaluation has demonstrated sonographic evidence of apparently healthy and well-perfused ovaries following detorsion despite their gross appearances. ${ }^{5}$ However, it's still controversial as there is always a reluctance to return a dark and oedematous ovary to the abdomen since pathologic features cannot be excluded only by gross inspection of the ovary.

In our case series, pathological features were found in the histopathological examination of all cases. Oltmann et al described 97 patients with ovarian torsion and benign pathology was present in $98 \%$ of cases. ${ }^{14}$ Less than half (10 of 22) of torsed ovaries contained cysts, teratomas or other benign masses as per the series published by Anders et al. ${ }^{18}$ 


\section{CONCLUSION}

Ovarian salvage is time-dependent and hence diagnosis of ovarian torsion needs to be done in timely manner. The diagnosis of ovarian torsion remains a challenge which often causes delay in operative intervention. Further, an assessment of the psychological impact of oophorectomy should be studied in order to facilitate the optimal tailored care. Hence forth, ovarian salvage is rare which is detrimental in paediatric age group. More randomized trials are needed to consider laparoscopic detorsion even in bluish oedematous ovary as first line of management.

Funding: No funding sources Conflict of interest: None declared

Ethical approval: Not required

\section{REFERENCES}

1. Hibbard LT. Adnexal torsion. Am J Obstet Gynecol. 1985; 152:456-61.

2. Bridgette DG, Mark DA, Elizabeth CP. Incidence and Trends of Pediatric Ovarian Torsion Hospitalizations in the United States, 2000- 2006. Pediatrics. 2010;125:532.

3. Hannah CC, Shweta B, Vikram SD. Pearls and Pitfalls in Diagnosis of Ovarian Torsion. RadioGraphics. 2008;28:1355-68.

4. Jennifer Eng-Lunt, Heather A, Jahn A. Pediatric and Adolescent Ovarian Torsion. ACEP News. 2011.

5. Poonai N, Poonai C, Lim R, Lynch T. Pediatric ovarian torsion: case series and review of the literature. Canadian Journal of Surgery. 2013;56(2):103-8.

6. Anders JF, Powell EC. Urgency of Evaluation and Outcome of Acute Ovarian Torsion in Pediatric Patients. Arch Pediatr Adolesc Med. 2005;159(6):532-5.

7. Lo LM, Chang SD, Horng SG, Yang TY, Lee CL, Liang CC. Laparoscopy versus laparotomy for surgical intervention of ovarian torsion. J Obstet Gynaecol Res. 2008;34(6):1020-5.

8. Tsafrir Z, Azem F, Hasson J, Solomon E, Almog B, Nagar H. Risk factors, symptoms and treatment of ovarian torsion in children: the twelve-year experience of one centre. J Minim Invasive Gynecol. 2012;19(1):29-33.
9. Ashwal E, Krissi H, Hiersch L, Less S, Eitan R, Peled Y. Presentation, Diagnosis and Treatment of Ovarian Torsion in Premenarchal Girls. J Pediatr Adolesc Gynecol. 2015;28(6):526-9.

10. Oskayli MC, Durakbasa, Masrabaci, Mutus, Zemheri IE, Okur H. Surgical Approach to Ovarian Torsion in Children. J Pediatr Adolesc Gynecol. 2015;28(5):343-7.

11. Smail A. Acute ovarian torsion in young girls. Journal of Acute Disease. 2016;1:59-61.

12. Kokoska ER, Keller MS, Weber TR. Acute ovarian torsion in children. Am J Surg. 2000;180:462-5.

13. Shauna D, Esther O, Susanna IL. Ovarian Torsion: Diagnostic features on CT and MRI with Pathologic Correlation. American Journal of Roentgenology. 2012;198(2):122-31.

14. Oltmann SC, Fischer A, Barber R, Huang R, Hicks B, Garcia N. Cannot exclude torsion - a 15-year review. J Pediatr Surg. 2009;44(6):1212-6.

15. Ganer HH, Shalev A, Ginat S, Kerner R, Keidar R, Bar J. Clinical characteristics of adnexal torsion in premenarchal patients. Arch Gynecol Obstet. 2016;293(3):603-8.

16. Bellet GC, Gehri M, Joseph JM, Pauchard JY. Is it Ovarian Torsion? A Systematic Literature Review and Evaluation of Prediction Signs. Pediatr Emerg Care. 2016;32(4):256-61.

17. Krissi H, Hiersch L, Aviram A, Ashwal E, Goldschmit, Peled Y. Factors Affecting Adnexal Torsion Direction: A Retrospective Cohort Study. Obstet Gynecol. 2016;81:405-10.

18. Jennifer FA, Elizabeth CP. Urgency of Evaluation and Outcome of Acute Ovarian Torsion in Pediatric Patients. Arch Pediatr Adolesc Med. 2005;159(6):532-5.

19. Claudio S, Irene B, Valentina P, Josephine L, Elisabetta A, Luca N. Adnexal torsion in children and adolescents: new trends to conservative surgical approach - Our experience and review of literature. Gynecological Endocrinology. 2013;29:1.

Cite this article as: Mishra V, Hokabaj S, Roy P, Aggarwal R, Vyas B, Mehta N. Case series of paediatric adnexal torsion: rare yet urgent entity. Int $\mathbf{J}$ Reprod Contracept Obstet Gynecol 2017;6:315-9. 